\title{
Randomized comparison of caregivers' ability to use epinephrine autoinjectors and prefilled syringes for anaphylaxis
}

\author{
Panadda Suwan, ${ }^{1}$ Phatcharee Praphaiphin, ${ }^{2}$ Pantipa Chatchate ${ }^{3}$
}

\begin{abstract}
Background: Caregivers often incorrectly use epinephrine autoinjectors. It is unclear whether this is due to insufficient training or a difficult-to-use tool. Furthermore, the high costs of epinephrine autoinjectors may limit their availability; so low-cost prefilled syringes may be the alternative.
\end{abstract}

Objectives and Methods: We performed a prospective randomized trial to compare successful epinephrine administration at four stages: after reading written instructions, and immediately after, 6 weeks, and 3 months following video training. The time required for successful epinephrine administration and failed steps in the administration of epinephrine autoinjectors and prefilled syringe were also investigated.

Results: Complete data analysis of 113 participants (prefilled syringe group, $\mathrm{n}=57$; EpiPen, $\mathrm{n}=56$ ) was performed. Significantly more participants correctly demonstrated the use of prefilled syringes compared to EpiPen after reading instructions, and immediately following 6 weeks, and 3 months after video training. ((adjusted OR 26.17 (95\%CI 8.2583.04), adjusted OR 4.07 (95\%CI 1.29-12.86), adjusted OR 14.01 (95\%CI 3.62-54.22)) and adjusted OR 31.44 (95\%CI 5.73172.39), respectively) Four key step errors would likely result in failure of administration and were more common with EpiPen $(14.0 \%$ vs. $2.3 \%, p<0.001)$. There were no statistically significant differences in time of successful administration between the two groups $(p>0.05)$.

Conclusion: Epinephrine prefilled syringe was significantly easier to use with a higher rate of correct use compared to EpiPen over time. All four key step errors in the administration were more likely with EpiPen. The time required for successful epinephrine administration was not significantly different.

Key words: anaphylaxis, epinephrine, autoinjectors, prefilled syringe, food allergy, caregivers' ability

\section{From:}

Department of Pediatrics, Faculty of Medicine Vajira Hospital,

Navamindradhiraj University, Bangkok, Thailand

Branch of Pediatric Nursing, Nursing Department,

Faculty of Medicine Vajira Hospital, Navamindradhiraj University, Bangkok, Thailand

${ }^{3}$ Department of Pediatrics, Faculty of Medicine,

Chulalongkorn University, King Chulalongkorn Memorial Hospital, Bangkok, Thailand

\section{Introduction}

The prevalence of anaphylaxis appears to be increasing. ${ }^{1-3}$ This may be due to more effective diagnosis by physicians, or due to a genuine increase in prevalence. It is is mainly caused by foods, drugs, and insects. ${ }^{4}$ The most common leading cause of anaphylaxis in children is food allergy. ${ }^{3,5}$ Epinephrine is the drug of choice for life-threatening allergic reactions and is needed immediately in anaphylactic patients in community

\section{Corresponding author:}

Panadda Suwan

Division of Allergy and Immunology, Department of Pediatrics, Faculty of Medicine Vajira Hospital, Navamindradhiraj University 681 Samsen Road, Dusit, Bangkok, Thailand

E-mail: panadda_lab@yahoo.com

and healthcare settings. ${ }^{6}$ Epinephrine administration by injection into the muscle layer of the anterolateral thigh is an appropriate position. ${ }^{4}$

The rise in prevalence of anaphylaxis is leading to the increased prescription of epinephrine. All patients with a history of anaphylaxis or patients who are allergic to foods that are likely to cause a severe allergic reaction, especially in patients 
allergic to nuts, fish and seafood, need to carry epinephrine at all times. ${ }^{7}$ Therefore, patients and caregivers must be aware of the indications for use of epinephrine, which is the initial treatment for anaphylaxis before reaching the hospital, including the need to be able to use it correctly and quickly. If this condition cannot be diagnosed or the initial treatment is delayed or incorrect, it may lead to death. ${ }^{4,8}$ Most anaphylaxis deaths occur in community settings rather than in healthcare settings. ${ }^{8}$ Thus, epinephrine injectors need to be easy to use and user-friendly devices. Previous studies have reported that only 25-50 percent of anaphylactic patients carry epinephrine..$^{9,10}$ Moreover, the patients carry epinephrine, but they don't use epinephrine (73 percent in adults ${ }^{11}$ and 83 percent in children). ${ }^{12}$ The reasons for patients or caregivers not using epinephrine might be lack of knowledge about indications for drug use, or how to use medication correctly, or a lack of adequate training. In addition, equipment design may make it difficult to use and thus reduce user confidence. Previous studies showed that patients or parents could use self-injectable epinephrine correctly in only 1 in 3 cases. $^{9}$

Epinephrine delivery systems used to treat anaphylaxis differ in their designs. Commercially available epinephrine autoinjectors are expensive, causing restrictions on use. Moreover, previous studies have found they are difficult to use and autoinjector accidents occur frequently, including finger injuries. ${ }^{13,14}$ Many studies have compared the functionality or usability of epinephrine autoinjector devices. ${ }^{15-18}$ In many countries worldwide, epinephrine autoinjectors remain unavailable or unaffordable, patients at risk for anaphylaxis are often provided with a manual prefilled syringe containing a premeasured epinephrine dose, however, there are some problems with stability and sterility about 2-3 months after preparation. ${ }^{19,20}$

EpiPen is the only autoinjector brand available in Thailand. The previous study assessing the use of self-administered EpiPen devices found that only 38\% of patients/parents, $21 \%$ of attending pediatricians and $36 \%$ of pediatric residents could accurately demonstrate the EpiPen device. ${ }^{9}$ Based on its difficult usage, the EpiPen was redesigned. The subsequent study found that more than $80 \%$ of parents and hospital staff correctly demonstrated all steps in use of the redesigned EpiPen. ${ }^{16}$ An epinephrine prefilled syringe is a low- cost therapeutic alternative to epinephrine autoinjectors. From the previous literature review, no study has compared the performance of the two devices.

In this study, a prospective randomized controlled trial, we compared the ability of caregivers of food-allergic children to successfully inject epinephrine using autoinjectors, the redesigned EpiPen and epinephrine prefilled syringe, after reading instructions, receiving standard video training, and whether they more easily recalled this information with usage at six weeks (primary outcome), three months after training. The secondary outcomes were evaluating the time required for successful epinephrine administration and the failed steps of epinephrine administration in each tool.

\section{Methods}

This prospective randomized controlled trial was approved by the Institutional Ethics Committee of the Faculty of Medicine, Vajira Hospital, Navamindradhiraj University. Inclusion criteria were participants who were responsible for taking care the food allergic children that they were diagnosed with combined skin prick test, serum IgE and clinical symptoms and gave informed consent prior to commencing this study. Exclusion criteria were participants who were healthcare personnel, unable to understand Thai, a history of, or having a child with, anaphylaxis, or having a child with high risk of anaphylaxis such as from tree nuts, peanut or seafood, or having a child with food allergy and a history of asthma which may be the reason for prescribed epinephrine injectors, ${ }^{7}$ have received previous education in use of an epinephrine injector, and have significant psychiatric problems. The participants were excluded if their children were prescribed epinephrine injectors during the study. The study was registered with www. clinicaltrials.in.th (TCTR20171127001).

We allocated caregivers of food-allergic children who met the inclusion criteria to a computer-generated randomization list to either the EpiPen group or prefilled syringe group and asked them to demonstrate the use of a 'trainer' device with a manikin after reading instructions and immediately after receiving standard video training. Epinephrine prefilled syringe was prepared from $0.3 \mathrm{ml}$ of a $1 \mathrm{mg} / \mathrm{ml}$ epinephrine solution in disposable plastic $1 \mathrm{ml}$. syringe with 25 -guages and 1 inch $(2.54 \mathrm{~cm})$ needle. After evaluating their ability to use epinephrine devices following video training, all participants in the prefilled syringe group and EpiPen group were individually shown the correct technique for their assigned epinephrine trainer device by a single specialist pediatric allergist and asked to immediately demonstrate its use with complete accuracy and confidence. Participants' ability to recall the correct use of each device at 6 weeks and 3 months after initial training in a standard situation was evaluated. Before the reassessment (at 6 weeks and 3 months), the participants were asked to confirm that they had not been trained in the use of epinephrine devices during the intervening period. Participants were asked to suddenly demonstrate the trainer without retraining. All demonstrations were evaluated by the same two investigators. All demonstrations were videotaped for futher evaluation in case of disagreement between the two investigators.

\section{Outcome measures}

Primary outcome was the comparison of successful epinephrine administration using epinephrine autoinjectors, redesigned EpiPen, and prefilled syringe at six weeks after training. The four key steps for EpiPen administration were as follows: (i) remove blue safety cap; (ii) place the orange end of the device against the thigh; (iii) push down to activate; and (iv) hold device in place for 3 seconds for successful epinephrine delivery. ${ }^{17,21}$ For prefilled syringes the key steps were: (i) remove needle cap; (ii) place needle against the thigh; (iii) push down the needle on the thigh and needle up to the needle hub; and (iv) push syringe tabs completely for successful epinephrine administration. (Figure 1) The drug administration must be demonstrated step by step that cannot skip the step. 


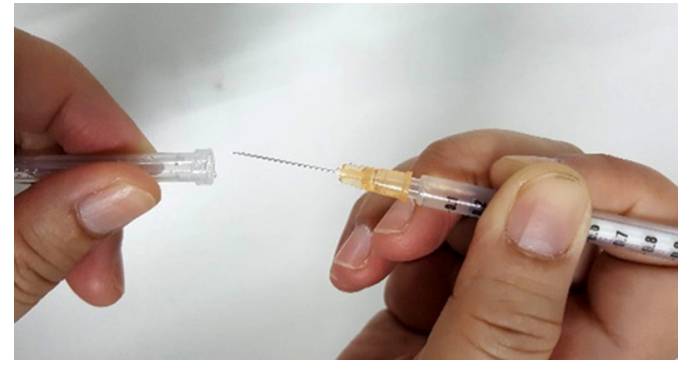

(i) remove needle cap

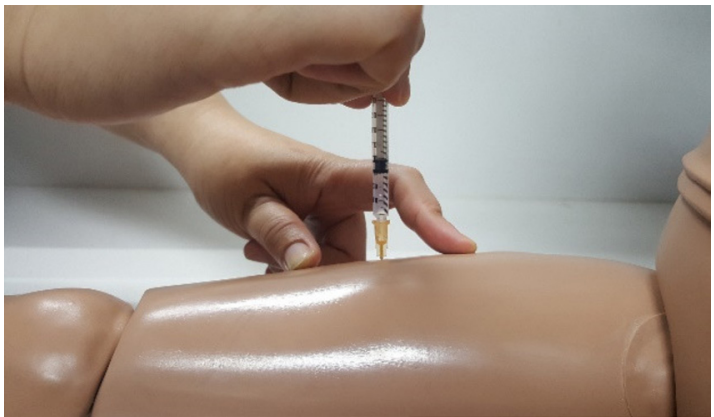

(iii) push down the needle on the thigh and needle up to the needle hub

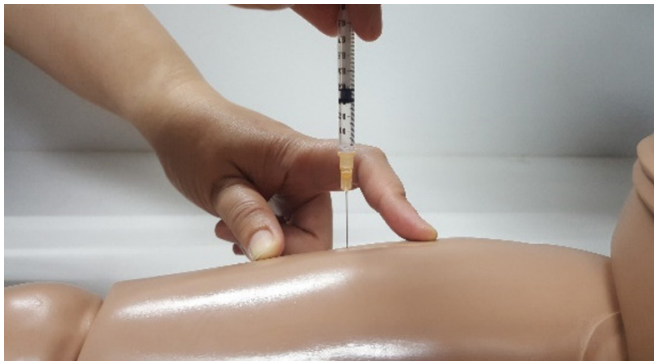

(ii) place needle against the thigh skin

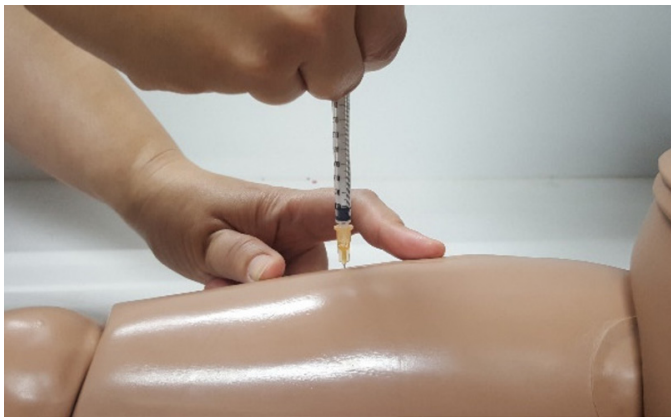

(iv) push syringe tabs completely for

successful epinephrine administration

Figure 1. The four key steps for epinephrine prefilled syringes administration

Secondary outcomes included comparing the rate of successful epinephrine administration between the two devices at three months after training, the time required for successful epinephrine administration, and the failed steps of epinephrine administration for each tool.

\section{Statistical analysis}

Data were analysed using SPSS (Statistical Package for the Social Sciences for Windows) version 22.0. Sociodemographic characteristics were compared to ensure comparability between the two groups. Categorical data were described as frequencies and analyzed with the Chi-square test. Continuous data and the time required for successful epinephrine administration at each time between groups were presented as mean \pm standard deviation or median and analyzed with the Student t-test or MannWhitney U-test for continuous data if they were non-normal distribution. The proportion of participants for each successful administration was compared between two groups at each of the time points using Pearson's chi-squared statistic or Fisher's exact test, and multiple logistic regression for adjusted analyses of binary outcomes to calculate adjusted odds ratios (OR) and $95 \%$ confidence intervals $(95 \% \mathrm{CI})$. Whether the differences in rates of successful epinephrine administration after reading instructions immediately, 6 weeks and 3 months after training was statistically significant or not was analyzed by McNemar test (within group). The cut-off of $p<0.05$ was used to determine statistical significance.

\section{Results}

The flow chart of participants is shown in Figure 2. Complete data analysis of 113 participants was performed (prefilled syringe group, $\mathrm{n}=57$; EpiPen group, $\mathrm{n}=56$ ). Characteristics of participants and food-allergic children are shown in Table 1.
The randomized groups were similar, except there was a difference in the respiratory manifestations of food allergy in the EpiPen group $(p=0.037)$.

\section{Ability to successfully administer epinephrine after reading in- structions, and immediately following, 6 weeks, and 3 months after video training}

After reading instructions, only $28.6 \%$ of caregivers in the EpiPen group were able to perform a successful administration of epinephrine, while $89.5 \%$ in the prefilled syringe group were able to perform successfully $(p<0.001)$. Six weeks after video training, the ability to recall steps in the use of the assigned trainer device was significantly higher in 53 of 57 (93\%) of the prefilled syringe group, compared to 34 of $56(60.7 \%)$ in the EpiPen group, after adjusting for age and education of caregivers, other underlying allergic diseases and the number of food allergies in patients (adjusted OR 14.01 (95\%CI 3.6254.22 ). Only $58.9 \%$ of participants demonstrated correct EpiPen use at 3 months, compared with $96.5 \%$ for prefilled syringe users. Successful epinephrine administration following reading the instructions, immediately, and 3 months after video training was significantly higher in the prefilled syringe group compared to the EpiPen group (adjusted OR 26.17 (95\%CI 8.25-83.04)), (adjusted OR 4.07 (95\%CI 1.29-12.86 and adjusted OR 31.44 (95\%CI 5.73-172.39), respectively (Table 2 ).

There was a significant difference in increased success rate of participants in EpiPen group after reading instructions and immediately after video training $(p<0.001)$ (Figure 3$)$. The differences in rates of successful epinephrine administration after complete training and 6 weeks, 3 months later decreased in the EpiPen group, however, this was not statistically significant $(p>0.05$, respectively). There was an increased rate of successful epinephrine administration after complete training and a 


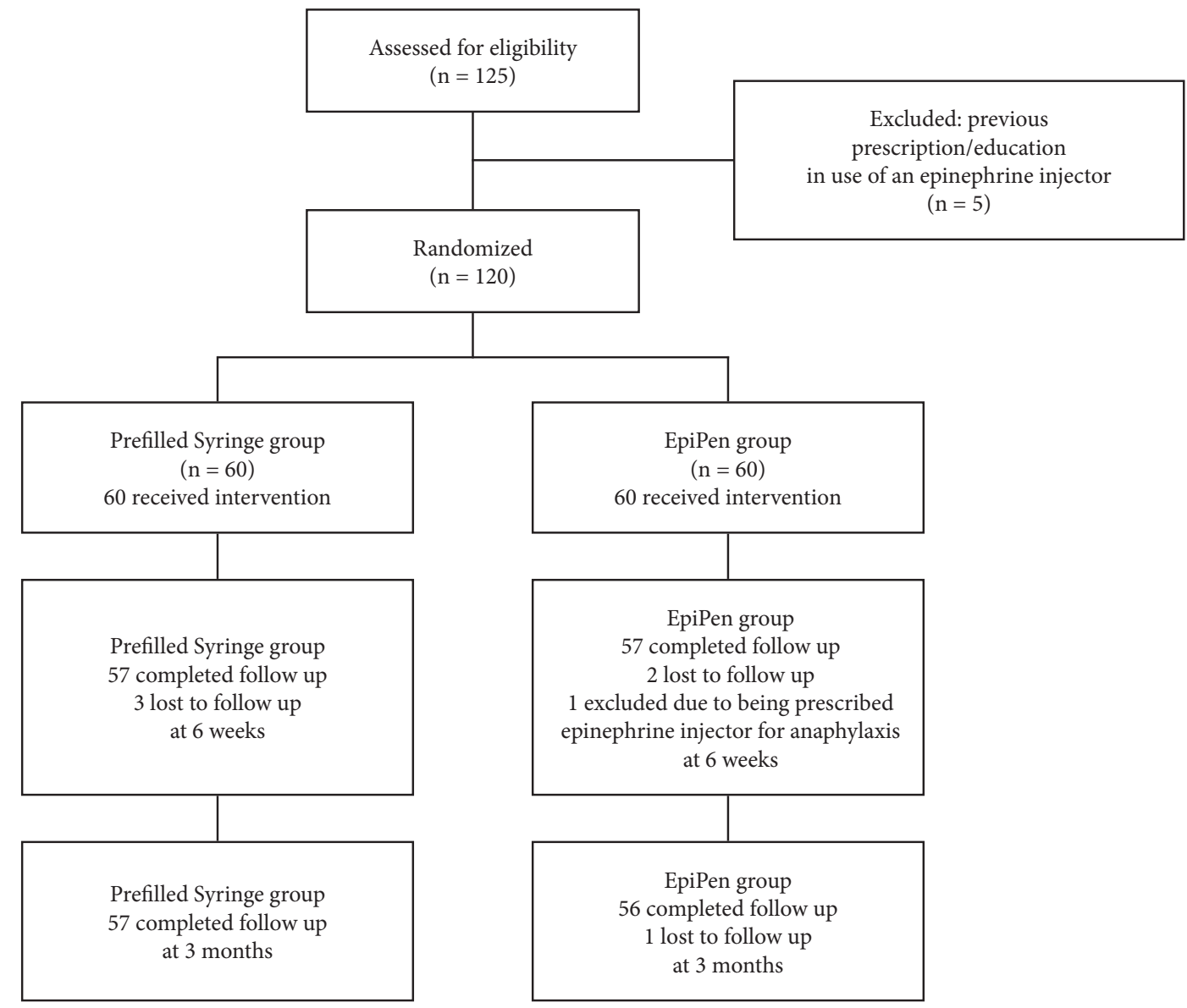

Figure 2. Study flow chart

Table 1. Demographic characteristics

\begin{tabular}{|c|c|c|}
\hline & $\begin{array}{c}\text { Prefilled syringe } \\
\text { group } \\
n=57(\%)\end{array}$ & $\begin{array}{l}\text { EpiPen group } \\
n=56(\%)\end{array}$ \\
\hline \multicolumn{3}{|c|}{ Demographic characteristics of participants } \\
\hline \multicolumn{3}{|l|}{ Age (years) } \\
\hline Median (IQR) & $39.33(35.00-49.00)$ & $41.42(32.50-49.00)$ \\
\hline \multicolumn{3}{|l|}{ Sex } \\
\hline Female & $43(75.4)$ & $48(85.7)$ \\
\hline \multicolumn{3}{|l|}{ Relationship to patients } \\
\hline Father & $8(14.0)$ & $4(7.1)$ \\
\hline Mother & $27(47.4)$ & $30(53.6)$ \\
\hline $\begin{array}{l}\text { Grandfather/Grand- } \\
\text { mother }\end{array}$ & $9(15.8)$ & $13(23.2)$ \\
\hline Others & $13(22.8)$ & $9(16.1)$ \\
\hline \multicolumn{3}{|l|}{$\begin{array}{l}\text { Education level of } \\
\text { caregivers }\end{array}$} \\
\hline Elementary School & $7(12.3)$ & $12(21.4)$ \\
\hline High School & $18(31.6)$ & $20(35.7)$ \\
\hline College & $8(14)$ & $8(14.3)$ \\
\hline Univesity & $23(40.4)$ & $15(26.8)$ \\
\hline Postgraduate & $1(1.7)$ & $1(1.8)$ \\
\hline \multicolumn{3}{|c|}{$\begin{array}{l}\text { Family income per month } \\
\text { (baht/month) }\end{array}$} \\
\hline$<10,000$ & $4(7)$ & $7(12.5)$ \\
\hline $10,001-30,000$ & $39(68.4)$ & $37(66.1)$ \\
\hline $30,001-50,000$ & $12(21.1)$ & $8(14.2)$ \\
\hline $50,001-80,000$ & $2(3.5)$ & $2(3.6)$ \\
\hline$>80,001$ & $0(0)$ & $2(3.6)$ \\
\hline
\end{tabular}

\begin{tabular}{|c|c|c|}
\hline & $\begin{array}{c}\text { Prefilled syringe } \\
\text { group } \\
n=57(\%)\end{array}$ & $\begin{array}{c}\text { EpiPen group } \\
n=56(\%)\end{array}$ \\
\hline \multicolumn{3}{|c|}{ Demographic characteristics of food-allergic children } \\
\hline \multicolumn{3}{|l|}{ Age (years) } \\
\hline Median (IQR) & $3.0(1.10-8.00)$ & $3.3(1.20-6.30)$ \\
\hline \multicolumn{3}{|l|}{$\begin{array}{l}\text { Clinical manifestation of } \\
\text { food allergy }\end{array}$} \\
\hline Skin changes & $49(86)$ & $48(85.7)$ \\
\hline Respiratory symptoms & $8(14.0)$ & $17(30.4)$ \\
\hline Gastrointestinal symptoms & $10(17.5)$ & $8(14.3)$ \\
\hline Cardiovascular symptoms & $0(0)$ & $1(1.8)$ \\
\hline Neurological symptoms & $0(0)$ & $0(0)$ \\
\hline \multicolumn{3}{|l|}{$\begin{array}{l}\text { Other allergic diseases of } \\
\text { patients }\end{array}$} \\
\hline Atopic dermatitis & $11(19.3)$ & $8(14.3)$ \\
\hline Allergic rhinitis & $5(8.8)$ & $12(21.4)$ \\
\hline Asthma & $1(1.7)$ & $0(0)$ \\
\hline \multicolumn{3}{|l|}{$\begin{array}{l}\text { The number of food } \\
\text { allergies }\end{array}$} \\
\hline 1 & $41(71.9)$ & $40(71.4)$ \\
\hline 2 & $10(17.6)$ & $9(16.1)$ \\
\hline$\geq 3$ & $6(10.5)$ & $7(12.5)$ \\
\hline
\end{tabular}

*Some children had more than 1 clinical manifestation of food allergy $\mathrm{IQR}=$ interquartile range 
Table 2. Comparision of successful epinephrine administration of prefilled syringe or EpiPen each time

\begin{tabular}{|c|c|c|c|c|c|c|}
\hline & $\begin{array}{l}\text { Prefilled syringe group } \\
\qquad \mathbf{n}=57(\%)\end{array}$ & $\begin{array}{l}\text { EpiPen group } \\
n=56(\%)\end{array}$ & $\begin{array}{c}\text { OR } \\
(95 \% \mathrm{CI})\end{array}$ & $p$ value & $\begin{array}{l}\text { Adjusted OR* } \\
\qquad(95 \% \mathrm{CI})\end{array}$ & $p$ value \\
\hline After reading instructions & $51(89.5)$ & $16(28.6)$ & $\begin{array}{c}21.25 \\
(7.62-59.26)\end{array}$ & $<0.001^{\star}$ & $\begin{array}{c}26.17 \\
(8.25-83.04)\end{array}$ & $<0.001^{\star}$ \\
\hline $\begin{array}{l}\text { Immeaditely after video } \\
\text { training }\end{array}$ & $52(91.2)$ & $40(71.4)$ & $\begin{array}{c}4.16 \\
(1.41-12.32)\end{array}$ & $0.010^{*}$ & $\begin{array}{c}4.07 \\
(1.29-12.86)\end{array}$ & $0.017^{\star}$ \\
\hline 6 weeks after training & $53(93)$ & $34(60.7)$ & $\begin{array}{c}8.57 \\
(2.72-27.06)\end{array}$ & $<0.001^{\star}$ & $\begin{array}{c}14.01 \\
(3.62-54.22)\end{array}$ & $<0.001^{*}$ \\
\hline 3 months after training & $55(96.5)$ & $33(58.9)$ & $\begin{array}{c}19.17 \\
(4.24-86.58)\end{array}$ & $<0.001^{*}$ & $\begin{array}{c}31.44 \\
(5.73-172.39)\end{array}$ & $<0.001^{*}$ \\
\hline
\end{tabular}

OR $=$ odds ratio; $95 \% \mathrm{CI}=95 \%$ confidence interval

${ }^{*}$ Adjusted OR $(95 \% \mathrm{CI})$; adjusted by age and education of caregivers, underlying other allergic diseases and the number of food allergies in patients

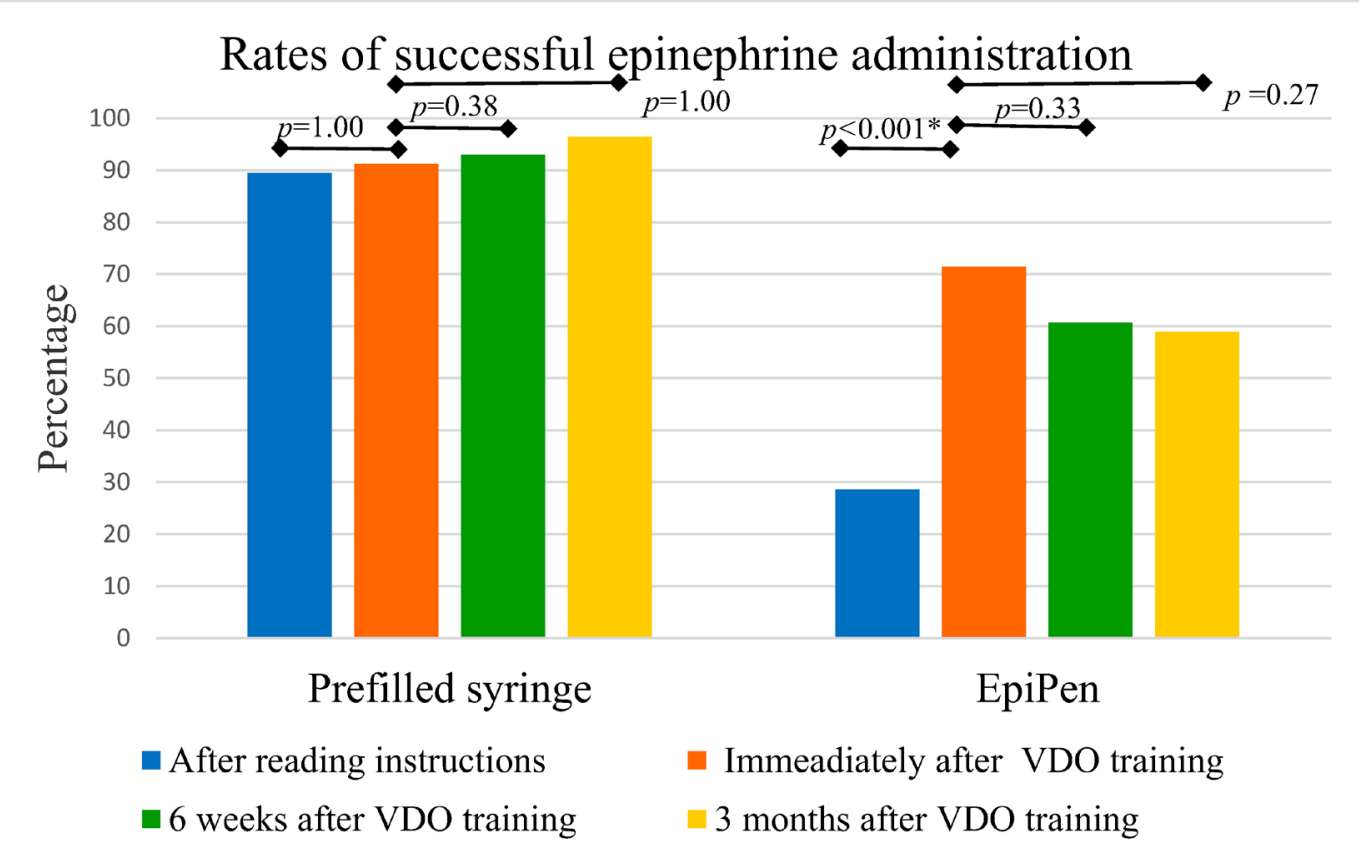

Figure 3. Rates of successful epinephrine administration in prefilled syringe group or EpiPen group after reading the instructions, and immediately, 6 weeks and 3 months after video training.

3-month period in the prefilled syringe group, however, there was no significant difference $(p>0.05)$ (Figure 3).

\section{Number of successful administrations of prefilled syringe or EpiPen device}

Participants in the prefilled syringe group were significantly more likely to demonstrate correct administration technique on all four assessment occasions compared to those in the EpiPen group $(47,82.5 \%$ in prefilled syringe group vs $9,16.1 \%$ EpiPen group; $p<0.001)$.

\section{Comparison of failed steps in epinephrine administration}

There are 'four key steps' for each device that if performed incorrectly result in failure to deliver epinephrine. We compared the two devices for failed steps each time and for total assessments (Figure 4). The cause of failure to deliver epinephrine may be due one or more steps. The frequent errors with EpiPens were failure to remove the blue safety cap (17\%), apply enough pressure to trigger the device (15.6\%), hold the device for a few minutes (12.9\%) and place orange end on thigh $(10.3 \%)$. For prefilled syringes it was not placing needle on thigh (3.1\%), pushing syringe tab completely (2.2\%), removing safety cap $(1.3 \%)$ and pushing the needle into the thigh (1.3\%).

Comparision of the steps needed to succesfully administer epinephrine and subsequent failures to demonstrate correct technique showed that the EpiPen group failed significantly more in all four key steps (step 1-4) compared to the prefilled syringe group in total assessments $(p<0.05)$ (Figure 4 ).

\section{Adverse event}

In the EpiPen group, 3 participants, 1 participant and 2 participants choosing the wrong end of the device for placement would have injected the digit after reading instruction, immediately after, and 3 months after video training, respectively. This adverse event did not occur in the prefilled syringe group hroughout the study. However, there was no significant 

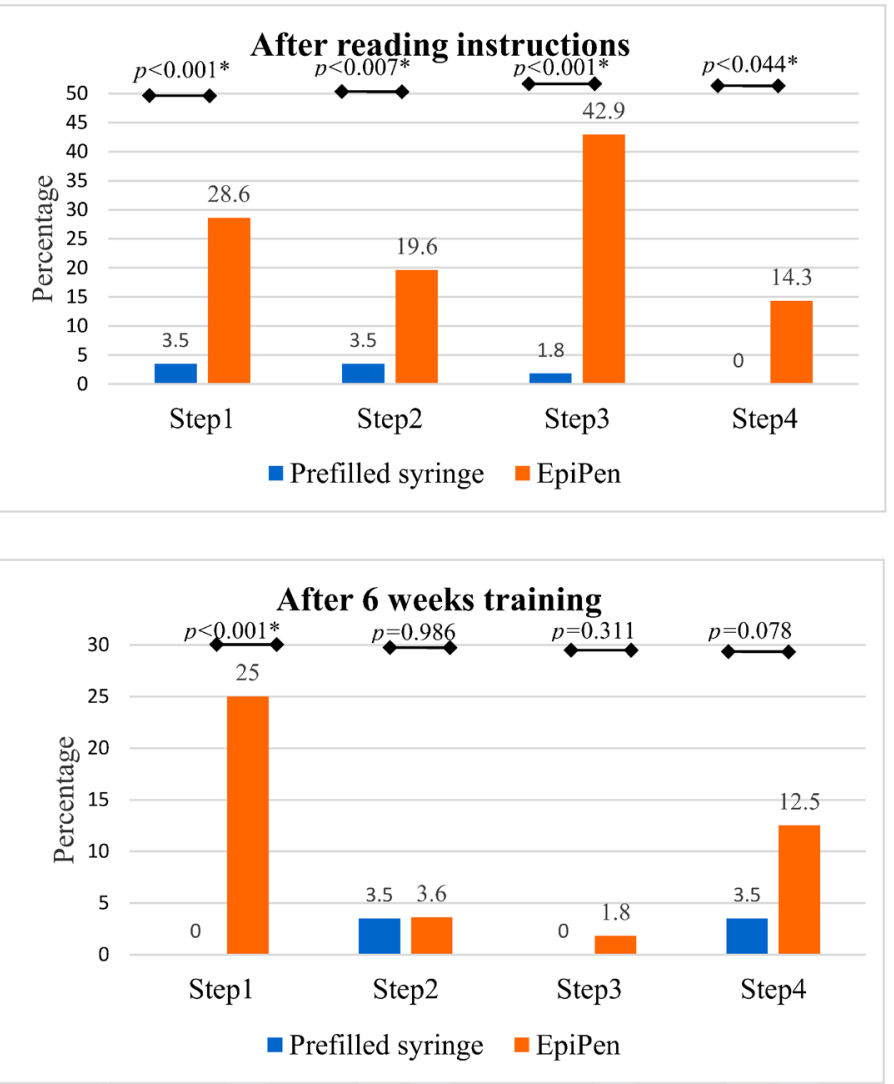
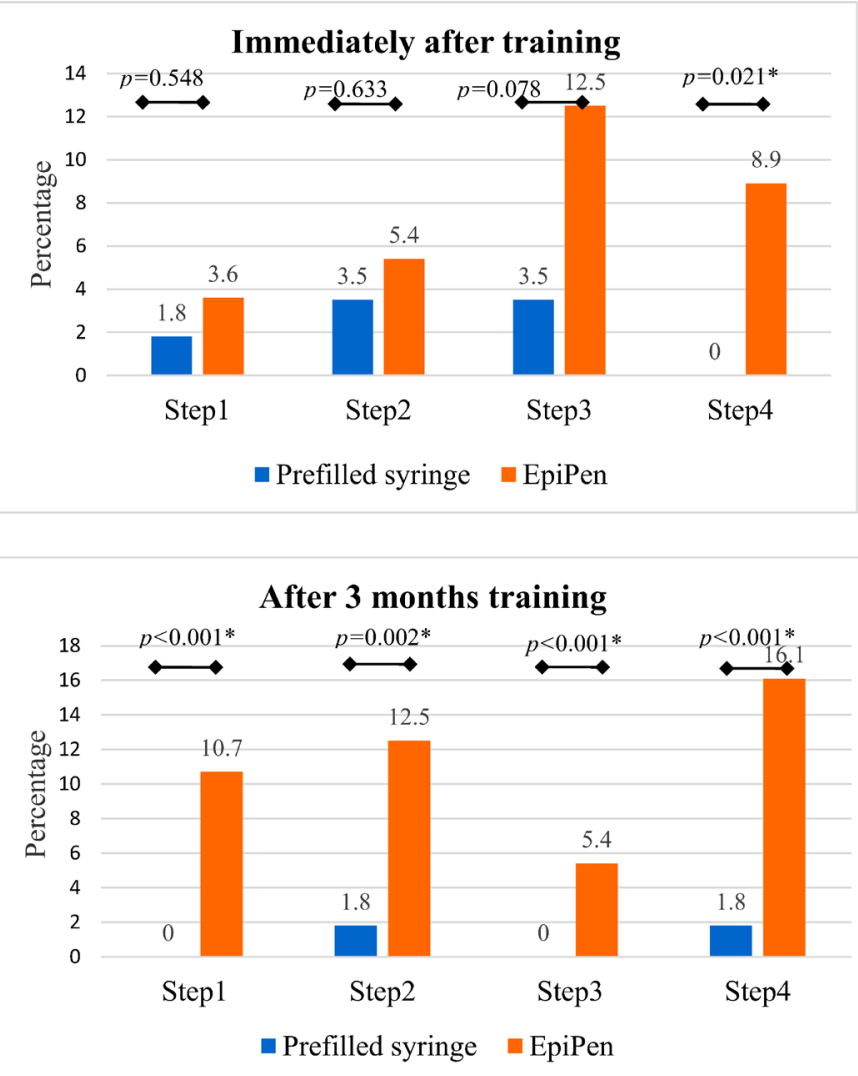

Figure 4. The failed steps of epinephrine device demonstration Step 1: removal of safety cap.

Step 2: placement of correct end of the device against the thigh.

Step 3: push down to activate EpiPen, push down the needle on the thigh and needle up to the needle hub in prefilled syringe. Step 4: holding device in place for 3 seconds in EpiPen, and pushing syringe tabs completely in prefilled syringe.

Table 3. The time required for successful epinephrine administration

\begin{tabular}{|c|c|c|c|}
\hline & $\begin{array}{l}\text { Prefilled } \\
\text { syringe } \\
\text { group }\end{array}$ & $\begin{array}{l}\text { EpiPen } \\
\text { group }\end{array}$ & $p$-value \\
\hline After reading instructions & $\mathrm{n}^{*}=51$ & $\mathrm{n}^{*}=16$ & 0.686 \\
\hline $\begin{array}{l}\text { Median time (sec) to } \\
\text { administer (IQR) }\end{array}$ & $\begin{array}{c}15.27 \\
(11.24-25.39)\end{array}$ & $\begin{array}{c}17.33 \\
(10.82-24.65)\end{array}$ & \\
\hline After video training & $\mathrm{n}^{*}=52$ & $\mathrm{n}^{*}=40$ & 0.506 \\
\hline $\begin{array}{l}\text { Median time (sec) to } \\
\text { administer (IQR) }\end{array}$ & $\begin{array}{c}11.92 \\
(8.34-16.19)\end{array}$ & $\begin{array}{c}10.92 \\
(7.81-16.33)\end{array}$ & \\
\hline 6 weeks after training & $\mathrm{n}^{*}=53$ & $\mathrm{n}^{*}=34$ & 0.429 \\
\hline $\begin{array}{l}\text { Median time (sec) to } \\
\text { administer (IQR) }\end{array}$ & $\begin{array}{c}11.86 \\
(9.70-15.45)\end{array}$ & $\begin{array}{c}10.58 \\
(8.57-14.27)\end{array}$ & \\
\hline 3 months after training & $\mathrm{n}^{*}=55$ & $\mathrm{n}^{*}=33$ & 0.207 \\
\hline $\begin{array}{l}\text { Median time (sec) to } \\
\text { administer (IQR) }\end{array}$ & $\begin{array}{c}12.43 \\
(9.87-15.31)\end{array}$ & $\begin{array}{c}10.58 \\
(8.27-13.64)\end{array}$ & \\
\hline
\end{tabular}

$\mathrm{n}^{*}=$ the number of participants who successfully administered epinephrine in each time

$\mathrm{IQR}=$ interquartile range

$\sec =$ second difference between groups with the frequency of accidental digital injection $(p>0.05)$.

\section{The time required for successful epinephrine administration}

The median time for successful administration was $11.86 \mathrm{sec}$ (IQR 9.70-15.45) using prefilled syringe devices, and $10.58 \mathrm{sec}$ (IQR 8.57-14.27) using EpiPens at 6 weeks after video training. There was no statistically significant difference. Additionally, the time required for successful epinephrine administration was not significantly statistically different between the two groups in the other 3 assessments. $(p>0.05$, Table 3$)$

\section{Discussion}

To our knowledge, this is the first study comparing epinephrine autoinjectors, the redesigned EpiPen, and prefilled syringe in ease of use and the ability to recall and demonstrate correct use at 6 weeks and 3 months after training.

Surprisingly, $89.5 \%$ participants were able to correctly demonstrate the use of prefilled syringes without prior training when allowed to read the instructions while only $28.6 \%$ of participants in the EpiPen group were able to demonstrate correct use. These results can be generalized to the general population, when anaphylaxis occurs in everyday life, that prefilled syringes are easier to use without training. The reading instructions appear to be an important factor supporting 
correct use, thus healthcare personnel should prepare the prefilled syringe, stored in a pencil case with written instructions, about when and how to use this device. Additionally, successful demonstration in the prefilled syringe groups was significantly 4 times, 14 times and 31 times more likely compared with the EpiPen group immediately after, 6 weeks and 3 months after video training. The findings may be generalized to caregivers that the prefilled syringe is significantly easier to use with high rates of success in epinephrine administration. Furthermore, there was a decline in the ability to correctly use Epipen (but not prefilled syringe) after a 6-week and 3-month period ( $p>0.05$, Figure 3 ).

Many studies have previously documented difficulties with the use of epinephrine autoinjectors by patients, caregivers and even medical practitioners., ${ }^{9,15,22}$ These findings were similar to previous studies of the original EpiPen that reported high rates of failed EpiPen use. A study of the redesigned EpiPen reported that most participants, including parents and hospital staff, correctly demonstrated all steps in the use of the redesigned EpiPen before, after training and 3 months of use (89, 100 and 87\%, respectively). ${ }^{16}$ However, a survey of community pharmacists found that only $62.1 \%$ could accurately demonstrate to a 'patient' how to use the redesigned EpiPen. ${ }^{23}$ Similarly, our result found that $71.4 \%$ of participants were able to successfully administer the redesigned EpiPen after immediate video training. The participants in the EpiPen group were able to demonstrate the increasingly correct use immediately after video training $(p<0.001)$. These findings found that $60 \%$ of the participants who initially did not use their EpiPen device correctly were then able to do so immediately after receiving standard video training. This suggests that the EpiPen is difficult to use when reading instructions and also that video training can greatly assist with correct use. This confirms that caregiver training has an important role in correctly using autoinjectors. ${ }^{24,25}$ After being optimally trained, completely accurate and confident in using their trainer, only $60.7 \%$ of participants correctly demonstrated the four key steps in EpiPen use at 6 weeks compared with 93\% for the prefilled syringe (adjusted OR $=14.01 ; 95 \%$ CI 3.62-54.22). A previous study showed that among mothers of food-allergic children, $42.5 \%$ were able to administer epinephrine using a redesigned EpiPen in a simulated anaphylaxis scenario at 6 weeks following training. ${ }^{17}$ Our study occurs in the standard scenario where levels of stress are likely to be lower so successful administration is higher.

The prefilled syringe is easier to use than the EpiPen in 4 assessments. These findings may be explained by the fact that prefilled syringes were prepared from an ampule of epinephrine and a disposable plastic $1-\mathrm{mL}$ syringe with a needle that is similar to the injection of other medications or vaccinations, so the participants are familiar with the device. Interestingly, two participants in the prefilled syringe group massaged the site after injection in spite of it not being included in the instructions. It was suggested that they are familiar with this device in daily life. Additionally, previous studies have found that the length of the epinephrine autoinjectors' needle is sometimes not long enough to reach muscular tissue in the thighs of obese individuals. ${ }^{26}$ An epinephrine prefilled syringe was prepared from disposable plastic $1 \mathrm{~mL}$ syringes and suitable needle lengths can be chosen to adequately give epinephrine intramuscularly. Thigh circumference, body mass index (BMI) and body weight are useful predictors for assessing needle length. ${ }^{27}$

Four key step errors that would result in failure to administer epinephrine were also more common with EpiPens compared to prefilled syringes in all 4 assessments. Our study adapted the 4 steps needed for successful EpiPen administration. This included holding the device in place for epinephrine delivery for 3 seconds because a previous study on epinephrine absorption suggested that holding the device in place for 1 second might be just as effective, ${ }^{28}$ thus EpiPen instructions suggest that the injection hold time is 3 seconds. ${ }^{21}$ The most common four key step errors in the use of the EpiPen, both after reading instructions and immediately after video training, was the failure to push down to activate. Similarly, the most frequent errors made with the old EpiPen were not exerting enough pressure to activate and quickly punching and holding the autoinjector for less than 5 seconds., ${ }^{9,22}$ Failure to remove the blue safety cap and failure to hold for 3 seconds were the most common key step errors at 6 weeks and 3 months, respectively. These results were similar to those reported by Umasunthar et.al, which showed that two common reasons for failure were $28.8 \%$ failed to remove all safety caps and $17.8 \%$ applied the autoinjector for less than 5 seconds using the redesigned EpiPen at 6 weeks. ${ }^{17}$

We compared step by step the causes of the failed step of epinephrine device demonstration. Failure to remove the blue safety cap (step 1) and failure to hold for 3 seconds (step 4) were significantly more common when using EpiPen compared to prefilled syringe in 3 assessments ( $p<0.05$, Figure 4). Participants took the EpiPen out of the skin immediately after the device had been triggered. These results were similar to a previous study that reported that only $47 \%$ using the current design of EpiPen could hold it in place. ${ }^{29}$ The results suggested these are important points for epinephrine autoinjector device developers to focus on and emphasize to caregivers all steps, especially the two common step errors, in action plans.

Accidental digital injection using the EpiPen was $2.68 \%$ but this adverse event did not occur in the prefilled syringe. Unintentional injection has led to digital ischemia in the caregivers $^{30}$ and failure to receive epinephrine to the child in need of it. This finding supported Simons et $\mathrm{al},{ }^{13}$ who reported in a systematic review of the hazards of unintentional injection of epinephrine autoinjectors that accidental injection is increasing.

The time required for successful epinephrine administration was not statistically significantly different between groups throughout the study. We demonstrated that video training on epinephrine injectors for caregivers shortened the time required for successful administration by 6 seconds in EpiPen and by 3 seconds in the prefilled syringe on average. The time to successfully administer in each device was similar in 2 assessments at 6 weeks and 3 months after video training (median time 12 seconds in prefilled syringe and 11 seconds in EpiPen)

The strengths of our study includes that it is a prospective randomized design investigating caregivers with food allergic children. All participants are representatives who may, in the 
near future, have to actually use this device. Because food allergy is the most common cause of anaphylaxis in children., A previous study found that participants, including hospital staff, were commonly able to administer epinephrine using an epinephrine trainer but the results cannot be generalized to people who will actually use this device. ${ }^{16}$ Epinephrine autoinjector devices are restricted or unavailable in some countries. One recent study reported that the most common problem in the use of epinephrine was lack of availability. ${ }^{31}$ Thus, our results suggested epinephrine prefilled syringe is a user-friendly and available device. Moreover, with epinephrine autoinjectors it is impossible to give an accurate dosage for infants and many children by using currently available autoinjectors with fixed epinephrine doses $(0.15$ or $0.3 \mathrm{mg})$. In contrast,prefilled syringes are prepared with an epinephrine dose based on $\mathrm{mg} / \mathrm{kg}$ for body weight of patient but should be prepared by trained healthcare professionals for accurate epinephrine doses and prompt use. ${ }^{32}$ However, the limitation of epinephrine prefilled syringes is the need to replace them every 3 months due to stability. ${ }^{19,20}$

Our study has some potential limitations. Firstly, this study was not performed in settings with actual intances of anaphylaxis. It is possible that more frequent errors would have occurred in the stressful environment of acute anaphylaxis. Secondly, this study was performed with demonstrations using the trainer and a manikin. The prefilled syringe with a needle was also a trainer so the participants could not demonstrate with their children because of ethical considerations. Needle phobia may also be a key barrier to the use of epinephrine prefilled syringe in real life situations. Thirdly, there was the absence of gold standard test to diagnose food allergy, double blind placebo controlled food challenge. (DBPCFC). Lastly, this study cannot blind the investigators, it may be caused the measurement bias, thus we observed with the same two investigators for reduced bias. If a disagreement between the two investigators occurred, video recordings were used to decide whether epinephrine would have been successfully delivered.

In conclusion, our study suggested that epinephrine prefilled syringe can be an appropriate alternative device for anaphylactic patients because of ease, ability to recall usage, and safety. Additionally, the low cost of prefilled syringes increases patients access to them.

\section{Acknowledgements}

This study was supported by a research promotion fund, Faculty of Medicine Vajira Hospital, Navamindradhiraj University, Bangkok, Thailand. We would like to thank all participants.

\section{Conflict of interest}

The authors declare no conflict of interest.

\section{References}

1. Jirapongsananuruk O, Bunsawansong W, Piyaphanee N, Visitsunthorn $\mathrm{N}$, Thongngarm T, Vichyanond P. Features of patients with anaphylaxis admitted to a university hospital. Ann Allergy Asthma Immunol. 2007;98: 157-62.

2. Techapornroong M, Akrawinthawong K, Cheungpasitporn W, Ruxrungtham K. Anaphylaxis: a ten years inpatient retrospective study. Asian Pac J Allergy Immunol. 2010;28:262-9.
3. Lee S, Hess EP, Lohse C, Gilani W, Chamberlain AM, Campbell RL. Trends, characteristics, and incidence of anaphylaxis in 2001-2010: A population -based study. J Allergy Clin Immunol. 2017;139:182-8.e2.

4. Simons FE. Anaphylaxis. J Allergy Clin Immunol. 2010;125(2 Suppl 2): S161-81.

5. Grabenhenrich LB, Dolle S, Moneret-Vautrin A, Kohli A, Lange L, Spindler T, et al. Anaphylaxis in children and adolescents: The European Anaphylaxis Registry. J Allergy Clin Immunol. 2016;137:1128-37.e1.

6. Muraro A, Roberts G, Clark A, Eigenmann PA, Halken S, Lack G, et al. The management of anaphylaxis in childhood: position paper of the European academy of allergology and clinical immunology. Allergy. 2007;62:857-71.

7. Rudders SA, Banerji A. An update on self-injectable epinephrine. Curr Opin Allergy Clin Immunol. 2013;13:432-7.

8. Bock SA, Munoz-Furlong A, Sampson HA. Further fatalities caused by anaphylactic reactions to food, 2001-2006. J Allergy Clin Immunol. 2007;119:1016-8.

9. Sicherer SH, Forman JA, Noone SA. Use assessment of self-administered epinephrine among food-allergic children and pediatricians. Pediatrics. 2000;105:359-62.

10. DeMuth KA, Fitzpatrick AM. Epinephrine autoinjector availability among children with food allergy. Allergy Asthma Proc. 2011;32:295-300.

11. Simons FE, Clark S, Camargo CA Jr. Anaphylaxis in the community: learning from the survivors. J Allergy Clin Immunol. 2009;124:301-6.

12. Noimark L, Wales J, Du Toit G, Pastacaldi C, Haddad D, Gardner J, et al. The use of adrenaline autoinjectors by children and teenagers. Clin Exp Allergy. 2012;42:284-92.

13. Simons FE, Lieberman PL, Read EJ Jr, Edwards ES. Hazards of unintentional injection of epinephrine from autoinjectors: a systematic review. Ann Allergy Asthma Immunol. 2009;102:282-7.

14. Arga M, Bakirtas A, Topal E, Yilmaz O, Hacer Ertoy Karagol I, Demirsoy MS, et al. Effect of epinephrine autoinjector design on unintentional injection injury. Allergy Asthma Proc. 2012;33:488-92.

15. Brown J, Tuthill D, Alfaham M, Spear E. A randomized maternal evaluation of epinephrine autoinjection devices. Pediatr Allergy Immunol. 2013;24: 173-7.

16. Robinson MN, Dharmage SC, Tang ML. Comparison of adrenaline auto-injector devices: ease of use and ability to recall use. Pediatr Allergy Immunol. 2014;25:462-7.

17. Umasunthar T, Procktor A, Hodes M, Smith JG, Gore C, Cox HE, et al. Patients' ability to treat anaphylaxis using adrenaline autoinjectors: a randomized controlled trial. Allergy. 2015;70:855-63.

18. Guerlain S, Hugine A, Wang L. A comparison of 4 epinephrine autoinjector delivery systems: usability and patient preference. Ann Allergy Asthma Immunol. 2010;104:172-7.

19. Kerddonfak S, Manuyakorn W, Kamchaisatian W, Sasisakulporn C, Teawsomboonkit W, Benjaponpitak S. The stability and sterility of epinephrine prefilled syringe. Asian Pac J Allergy Immunol. 2010;28:53-7.

20. Rawas-Qalaji M, Simons FE, Collins D, Simons KJ. Long-term stability of epinephrine dispensed in unsealed syringes for the first-aid treatment of anaphylaxis. Ann Allergy Asthma Immunol. 2009;102:500-3.

21. Greenberger PA, Wallace DV, Lieberman PL, Gregory SM. Contemporary issues in anaphylaxis and the evolution of epinephrine autoinjectors: What will the future bring? Ann Allergy Asthma Immunol. 2017;119:333-8.

22. Mehr S, Robinson M, Tang M. Doctor--how do I use my EpiPen? Pediatr Allergy Immunol. 2007;18448-52.

23. Salter SM, Loh R, Sanfilippo FM, Clifford RM. Demonstration of epinephrine autoinjectors (EpiPen and Anapen) by pharmacists in a randomised, simulated patient assessment: acceptable, but room for improvement. Allergy Asthma Clin Immunol. 2014;10:49.

24. Kim JS, Sinacore JM, Pongracic JA. Parental use of EpiPen for children with food allergies. J Allergy Clin Immunol. 2005;116(1):164-8.

25. Arkwright PD, Farragher AJ. Factors determining the ability of parents to effectively administer intramuscular adrenaline to food allergic children. Pediatr Allergy Immunol. 2006;17:227-9.

26. Stecher D, Bulloch B, Sales J, Schaefer C, Keahey L. Epinephrine auto-injectors: is needle length adequate for delivery of epinephrine intramuscularly? Pediatrics. 2009;124:65-70

27. Manuyakorn W, Bamrungchaowkasem B, Ruangwattanapaisarn N, Kamchaisatian W, Benjaponpitak S. Needle length for epinephrine prefilled syringes in children and adolescents: Is it one inch? Asian Pac J Allergy Immunol. [Preprint].2017[cited 2018 Jan 15]:[7p.]. Available from: http:// apjai-journal.org/wp-content/uploads/2017/09/AP-020317-0039.pdf 


\section{APJAI}

28. Baker TW, Webber CM, Stolfi A, Gonzalez-Reyes E. The TEN study: time epinephrine needs to reach muscle. Ann Allergy Asthma Immunol. 2011; 107:235-8.

29. Camargo CA Jr, Guana A, Wang S, Simons FE. Auvi-Q versus EpiPen: preferences of adults, caregivers, and children. J Allergy Clin Immunol Pract. 2013;1:266-72.e1-3.

30. Velissariou I, Cottrell S, Berry K, Wilson B. Management of adrenaline (epinephrine) induced digital ischaemia in children after accidental injection from an EpiPen. Emerg Med J. 2004;21:387-8.
31. Cohen MB, Saunders SS, Wise SK, Nassif S, Platt MP. Pitfalls in the use of epinephrine for anaphylaxis: patient and provider opportunities for improvement. Int Forum Allergy Rhinol. 2017;7:276-86.

32. Simons FE, Chan ES, Gu X, Simons KJ. Epinephrine for the out-of-hospital (first-aid) treatment of anaphylaxis in infants: is the ampule/syringe/needle method practical? J Allergy Clin Immunol. 2001;108:1040-4. 